\title{
Peri-implantitis. Part 2: Prevention and maintenance of peri-implant health
}
IN BRIEF
- Reviews potential modifiable and non- modifiable risk factors for per-implantitis development.
- Details strategies for the prevention of peri-implantitis.
- Proposes an implant maintenance protocol and schematic for maintenance visits.

The prevention of any disease process should be the cornerstone of any healthcare provision. This ethos is well established in dentistry with plaque associated disease such as periodontitis and caries but is at the current time less developed for peri-implantitis. The current review identities potential modifiable and non-modifiable risk factors for per-implantitis development and details strategies for the prevention of the disease. These include poor oral hygiene, previous history of periodontitis, smoking, genetic factors, occlusal overload and foreign body reactions. Local factors include soft tissue and bone quality, implant positioning, restoration design and the implant-abutment interface. An implant maintenance protocol is proposed and a schematic for maintenance visits is also detailed.

\section{INTRODUCTION}

Preventing the occurrence of future disease is a fundamental component of dental practice; indeed, the prevention of plaque-associated diseases such as caries and periodontitis is a central feature of dental public health strategies across the world. ${ }^{1}$

Part one of this series of highlighted the importance a preventive ethos has to play when planning implant therapy due to the adverse consequences that result from peri-implantitis and the lack of established or predictably effective treatments for the condition. ${ }^{2,3}$

The preventive approach should begin at the outset, with appropriate case selection, and early, effective education of the patient about their role in preventive and maintenance strategies. Clinicians need to be aware of risk factors associated with the development of peri-implantitis and communicate these to the patient before implant placement. The need for ongoing maintenance following implant placement and the acceptance of the time required and costs for the necessary professional support should be outlined and documented during the consent process. Patient awareness and

'Department of Restorative Dentistry, Kings College Hospital, Denmark Hill, London, SE5 9RS;

2Department of Restorative Dentistry, Maxillofacial Unit, Morriston Hospital, Swansea, SA6 6NL

${ }^{*}$ Correspondence to: Aws Alani

E-mail: awsalani@hotmail.com

\section{Refereed Paper}

Accepted 10 June 2014

DOI: 10.1038/sj.bdj.2014.809

${ }^{\circledR}$ British Dental Journal 2014; 217: 289-297

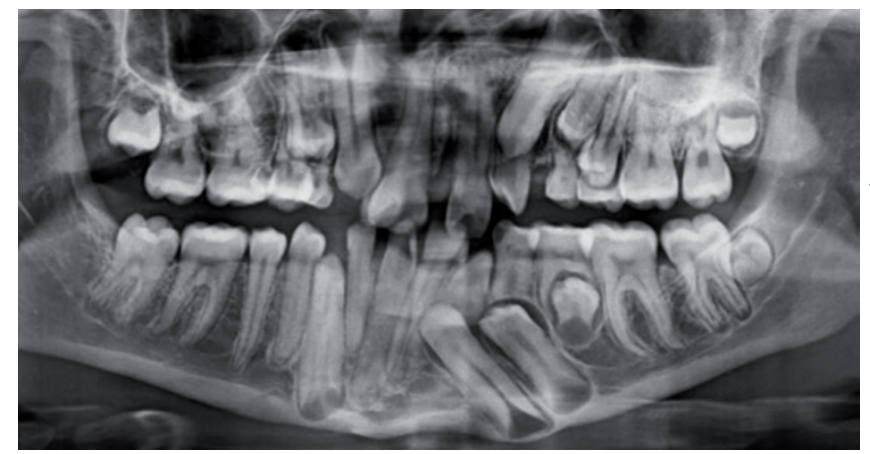

Fig. 1a This patient presented complaining of a crowded dentition and commonly managed plaque associated diseases

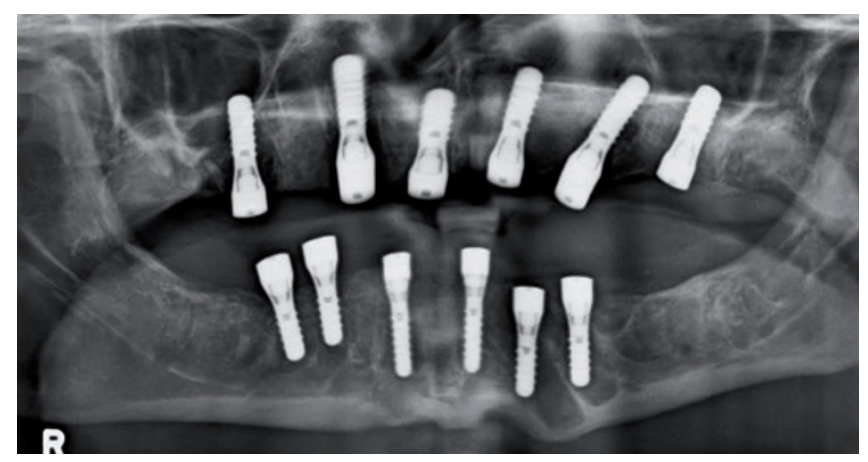

Fig. 1b Unfortunately in favour of management of the orthodontic issues and carious lesions the patient was edentulated and provided with a number of implants the majority of which had compromised angulations

commitment should occur well in advance of any implant placement.

\section{CASE SELECTION}

The implication of possible implant failure needs to be a major consideration when choosing between methods of tooth replacement. In addition, when comparing treatment options there needs to be a full and objective appreciation of the advantages and disadvantages of all treatment options including providing no treatment. The best interests of the patient in the short and long term must be paramount. The clinician has a professional responsibility to work within his/her competencies, ensure the patient is fully informed and provide the most appropriate care.

The patient will also require comparative information between conventional and implant prostheses, as well as what would be the sequelae if no treatment is provided. The clinician must be able to provide unbiased and robust information about all the treatment options. This is essential to make the consent more robust and the whole process transparent for both the providing clinician and the patient (Fig. 1). 


\section{PATIENT EXPECTATIONS AND EDUCATION}

Where patients are under the misconception that implants are 'just like natural teeth' the medico-legal implications become magnified. ${ }^{4}$ It should be clear from the consent process and the information provided before and during treatment planning that implants are not similar to teeth despite historic claims to the contrary. Indeed implants often require greater attention than their natural counterparts in respect to maintenance and monitoring. ${ }^{5}$ This important fact may escape the consent process despite the clinician's best intentions (Fig. 1).

It may be difficult for a clinician to answer robustly and confidently all queries raised by patients in respect to proposed implant treatment. Research into newly developed implant techniques has been shown to be rarely prospective with a good scientific basis. ${ }^{6,7}$ It could be argued that research and development should be channelled into the management of implant complications as opposed to the success of new implant designs.

The benefits of utilising effective patient education in preventing periodontitis have long been established. ${ }^{8}$ Unfortunately, the body of evidence to support the role of patient education in the prevention of peri-implantitis is comparatively sparse and largely based on opinion. ${ }^{9,10}$ Indeed, a systematic review published in 2012 identified only seven studies that examined techniques in the prevention of periimplantitis. ${ }^{11}$ Disappointingly, the results showed that the quality of the research was low and surrogate as opposed to true outcomes measures. ${ }^{11}$ Despite this lack of clear evidence, it is difficult to counter the argument that patient education is a fundamental aspect of implant therapy. ${ }^{12}$ Patient understanding and awareness of potential complications is likely to aide prevention and early detection of periimplant disease. ${ }^{13}$

\section{RISK FACTORS}

As with any disease process the presence of certain risk factors will increase the likelihood of disease development and progression. Awareness of these risk factors when planning implant treatment is important in the prevention of the disease (Table 1).

\section{Oral hygiene}

As plaque is the main aetiological factor causing biofilm development around both teeth and implants it is unsurprising to find a close association between peri-implant bone loss and poor oral hygiene. ${ }^{14,15}$ The

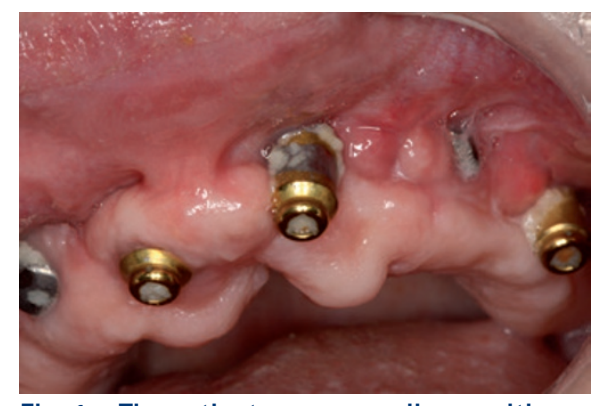

Fig. 1c The patients poor compliance with oral hygiene measures continued and she developed peri-implantitis on all implants resulting in the need for explantation

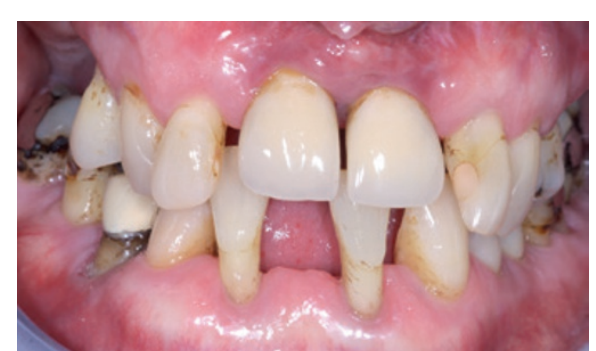

Fig. 2 A patient presenting with ongoing periodontal disease and peri-implantitis on implants in the 11 and 21 sites. Note the marked extent of gingivitis adjacent to the implants. The patient was not aware that periodontal disease provided increased risk for the development of biological complications with her implants

relationship between peri-implant disease and full mouth plaque scores has been shown to be strong and dose dependent, with poor oral hygiene being highly associated with peri-implantitis. ${ }^{15}$ Indeed patients with poor oral hygiene have been shown to be up to 14 times at a greater odds of developing peri-implantitis. ${ }^{17}$ In a cohort of 23 patients with 109 implants, only 4\% of the implants in patients with optimal oral hygiene presented with peri-implantitis. This was in contrast to $48 \%$ in patients with poor oral hygiene. ${ }^{16}$

Patients need to be made aware that implants are susceptible to plaque-related diseases in a very similar way to teeth. This preventable risk factor needs to be addressed well in advance of any planned implant treatment to prevent peri-implantitis.

At the treatment planning stage it is advised that an objective assessment of oral hygiene should be conducted and if this is suboptimal treatment should be delayed until plaque control has improved. Once this is achieved patients should be made aware of the need to maintain this indefinitely otherwise future susceptibility to periimplant diseases can develop. Optimal whole mouth plaque control is desired due to the possibility of translocation from remote intraoral sites to the implant surface. ${ }^{18}$

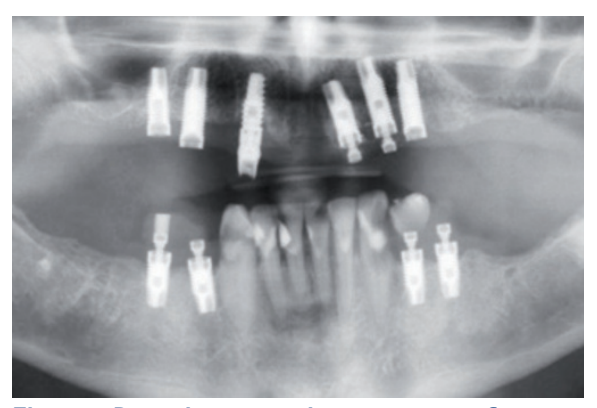

Fig. 3a Dental panoramic tomogram of a patient with a number of implants and failing natural dentition. She presented with a number of systemic co-morbidities for which she was consuming a number of medications for. She also smoked. Significant side effects of her poly pharmacy included xerostomia

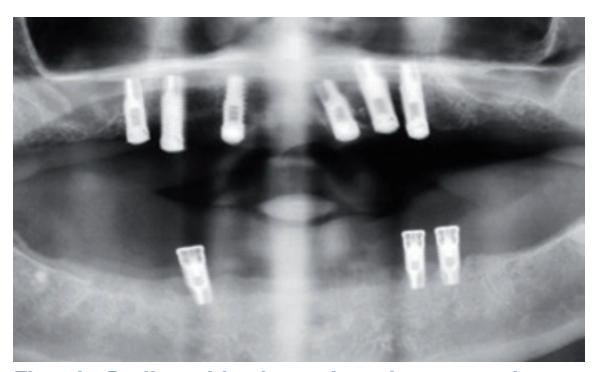

Fig. 3b Radiograhic view taken three years later. All teeth were extracted due to progressive decay and pulpal involvement. Peri-implantitis developed on the majority of implant fixtures. The patient was transitioned to removable dentures

Table 1 Potential risk factors for peri-implantitis

Local

Non-keratinised tissue

Thin gingival biotypes

Previous or current history of periodontally involved teeth

Poor bone quality

Poor angulation and bodily positioning of the implants

Cement excess

Surgical trauma

Implants placed immediately into extraction sockets

Augmented bone

Presence of autoimmune oral disease

\section{Restoration}

'Over-engineered' restorations with too many implants

Implants placed in close proximity making cleaning difficult

Fixed bridges with extensive flanges

Limited embrasure spacing between implants Restorations with extensive cantilevers increasing plaque retention

\section{Patient}

Previous or current history of smoking

Poor oral hygiene and compliance

History of parafunction and bruxism

\section{Systemic}

\section{Diabetes}

Systemic conditions or medications that can affect bone turnover, salivary output and natural body defences are likely to increase the risk to peri-implant infection. 


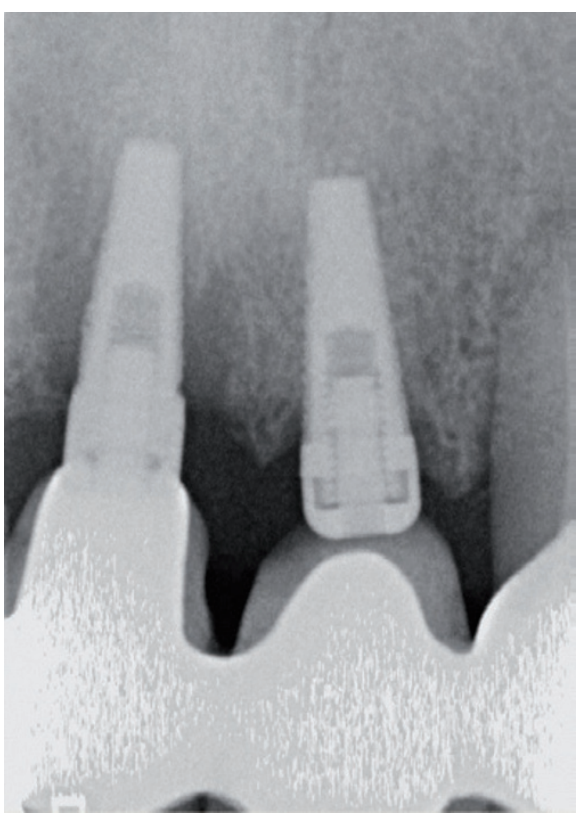

Fig. 4 Long cone periapical of implants placed in the 11 and 21 sites. These implants were placed to help support a multiple pontic and abutment bridge spanning the maxillary arch. Due to angulation issues the implant in the 21 site could not be engaged in the prosthesis. As a result of occlusal overload of the 11 marked bone loss resulted, this was in contrast to the 21 , which had significantly less bone loss

\section{Previous history of periodontitis}

Patients who have been previously treated for periodontitis, those who have current disease as well as those with a previous history of tooth loss due to periodontal disease are at an increased risk of developing peri-implantitis (Fig. 2). ${ }^{19}$ Research shows that a previous history of periodontitis makes a patient up to four times more likely to develop peri-implantitis. ${ }^{17}$ This increased risk of peri-implantitis needs to be made clear before the start of treatment.

The presence of residual pocketing in patients planned and provided with dental implants has also been investigated. ${ }^{20}$ Those patients with at least one residual periodontal pocket of $6 \mathrm{~mm}$ or greater showed a significantly greater prevalence of peri-implant bone loss, bleeding on probing than those patients who were periodontally stable. $^{20}$ This would suggest that the susceptibility of periodontally affected patients to peri-implantitis may continue indefinitely despite concerted efforts to render them periodontally healthy.

Therefore the importance of optimal hygiene is a pre-requisite if implantbased rehabilitation is being considered or has already been provided. Where active periodontal disease is present this requires a period of stabilisation and subsequent follow-up to ensure compliance before consideration for implant treatment. ${ }^{20}$

\section{Smoking}

The links between the progression of periodontitis and smoking are well established. ${ }^{21}$ Smokers have been shown to have greater amounts of plaque as well as poorer compliance with oral hygiene. ${ }^{22,23}$ As such it should be unsurprising that smokers have a significantly higher risk of developing marginal bone loss around implants than non-smokers. ${ }^{24}$ In fact, smokers have been shown to have five times greater odds of developing peri-implantitis than non-smokers. ${ }^{25}$ This increased risk should be a significant factor for patients when considering implants, especially where elective extraction is being proposed (Fig. 3).

A period of smoking cessation advice by either dentist, smoking cessation councillor or general medical practitioner should be encouraged where implants are to be considered..$^{26}$ Patients may cessate smoking until implant treatment is concluded and then recommence the habit. Unfortunately this, similarly to periodontal disease, is likely to affect the health of the peri-implant tissues and increase the likelihood of periimplantitis development. ${ }^{27,28}$

\section{SYSTEMIC FACTORS}

Patients with systemic conditions associated with altered bone physiology or impaired immune function may be considered at a greater risk of peri-implantitis than otherwise healthy individuals. ${ }^{29-31}$

For example, recent studies examining diabetic patients have shown a greater risk to peri-implantitis development especially if their blood glucose control is poor. ${ }^{32}$ Those patients with good glycaemic control show similar inflammatory markers to patients who were otherwise healthy. ${ }^{33}$ Patients with peri-implantitis and poor glycaemic control presented a similar inflammatory marker profile to those with chronic periodontitis. ${ }^{33}$

Chronic conditions affecting bone turnover such as radiotherapy and osteoporosis are considered risks for implant failure but as yet no formal research into their effects on peri-implantitis development have been

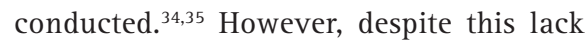
of research it would appear advisable to consider systemic conditions affecting bone turnover as a risk factor for peri-implantitis until robust evidence to the contrary becomes available.

The effect of medications on the oral cavity in respect to periodontitis have recently been reviewed..$^{36}$ When compared to healthy patients, those on systemic medications present with a more pathogenic biofilm on teeth due in part to a xerostomic oral environment. ${ }^{37-39}$ However, the implications of these findings on the development of peri-implantitis are not yet known. Studies have shown that peri-implantitis may be more prevalent in patients with cardiovascular disease and hepatitis (Fig. 3). ${ }^{40,41}$ The former may be related to the effect of medicinal treatment and their side effects on the oral cavity but there may be multifactorial factors present in these patient groups. As such and due to the current lack of evidence and potential for bias within the study population prospective studies examining the incidence of peri-implantitis are required.

Mucocutaneous autoimmune inflammatory diseases such as lichen planus have also been investigated in relation to peri-implantitis. In a prospective-controlled study on patients with implants and lichen planus it was found that $67 \%$ of subjects presented with peri-implant mucositis and 28\% with periimplantitis. ${ }^{42}$ These observations may be due to a hypothetical inability of the epithelium to adhere to the implant surface, mucosal distrurbances or a greater susceptibility to bone loss. ${ }^{43}$ However, a more recent publication illustrated an increased prevalence of peri-implantitis in patients with lichen planus but implant survival did not differ significantly to those without the condition. ${ }^{44}$

It seems that systemic disease can affect the development and progression of periimplantitis. Systemic status needs to be carefully considered at the treatment planning stages but also needs to be appreciated long term. Patients healthy at the implant placement stage may develop systemic disease in the future, which could affect the maintenance of osseointegration or increase susceptibility to peri-implantitis. Patients need to be aware of this possibility at the outset.

\section{GENETIC FACTORS}

As with periodontitis, genetic factors may make individuals more susceptible to periimplantitis although evidence is limited. ${ }^{45-47}$ A systematic review was unable to come to any firm conclusions on the potential association between IL-1 gene polymorphism and peri-implantitis, whereas a solitary study concluded that it was a significant risk factor. ${ }^{46,47}$ Further research is required confirm whether susceptibility to periimplantitis can be inherited genetically.

\section{OCCLUSAL OVERLOAD}

Patients who parafunction are likely to place non-axial loads on both teeth and implants for long periods. ${ }^{48-51}$ Since implants lack a periodontal ligament, when put under increased loading they do not have the ability to accommodate excessive stresses. Loading results in stress concentrated at the marginal bone around the implant. ${ }^{52}$ This 
may result in increased bone loss as this area remodels under the strain (Fig. 4)..$^{53}$

As such occlusal overload may be considered a risk factor in those with a history of parafunction (for example, previously fractured restorations or excessive attrition of teeth) or in those situations where the occlusal scheme is sub-optimal. In addition, occlusal factors may be more significant in edentulous patients who are restored with fixed implant restoration. In this situation loading especially during lateral movements cannot be shared with natural teeth. ${ }^{54}$

Bone loss due to excessive occlusal loading may lead to the implant surface becoming exposed and populated by microorganisms resulting in further bone loss. The effects of occlusal overload may therefore be magnified in patients with poor oral hygiene. ${ }^{48-51,53}$ This potential association was confirmed in a systematic review although biofilm development remains the primary aetiological factor. ${ }^{51}$

\section{HYPERSENSITIVITY, FOREIGN BODY REACTIONS AND PHYSICO-CHEMICAL ASPECTS}

Case reports have identified incidences of hypersensitivity to titanium fixtures. ${ }^{55-57}$ This can manifest clinically as peri-implant mucositis, which could potentially result in a peri-implantitis lesion. Other potential areas of disease development may be corrosion and galvanism of implant fixtures, which could potentially result in loss of integration resulting in surface exposure and secondary infection of the implant surface. ${ }^{58}$ The need for further research in this field has been identified. ${ }^{58}$

\section{IMPLANT SITE}

\section{Soft tissue quality}

The presence of keratinised tissue circumferentially around implants has long been cited as an important factor in longterm health of implant restorations. ${ }^{59}$ It is considered that the wider the area of keratinised tissue the more beneficial for overall health of the peri-implant tissues. A systematic review illustrated how periimplant keratinised tissue of less than $2 \mathrm{~mm}$ in width has been shown to be associated with increased peri-implant disease, plaque bleeding and scores. ${ }^{60}$ Similarly a recent systematic review showed that a lack of adequate keratinised mucosa is associated with more plaque accumulation, tissue inflammation, mucosal recession, as well as loss of peri-implant attachment (Fig. 5). ${ }^{61}$ This can be partly attributed to the mobility of mucosal tissue (non-keratinised) resulting in greater plaque accumulation in function. ${ }^{62}$

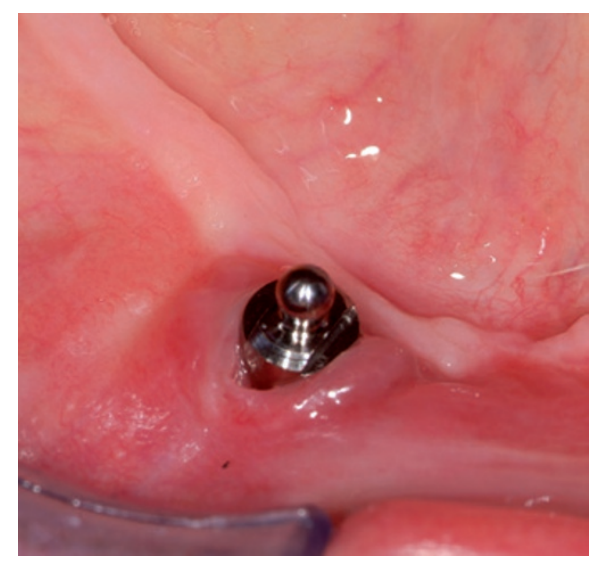

Fig. 5 Ball abutment supporting an overdenture placed outwith of the keratinised tissue margin. Such positioning can increase the risk of plaque impaction adjacent to the implant

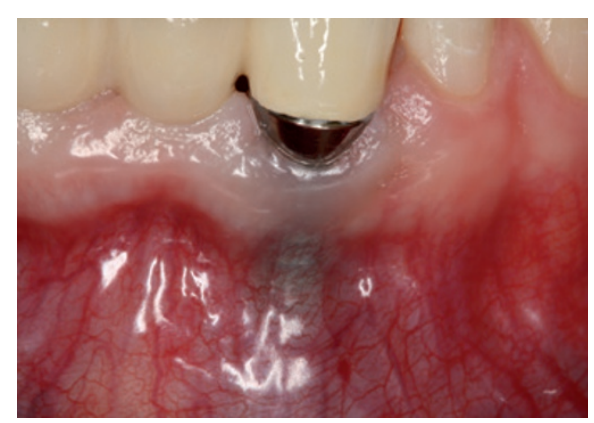

Fig. 6 Implant supported bridgework in the anterior mandible. The $\mathbf{3 2}$ site was grafted before implant placement. At ten year review the grafted bone had resorbed revealing a grey hue of the implant. Any further soft tissue changes to this site such as recession is likely to result in bacterial population of the implant threads once exposed

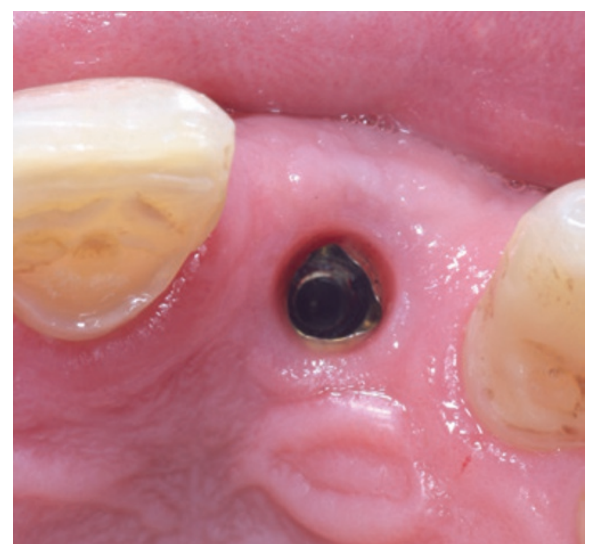

Fig. 7a Implant placed in the 21 site. Note the superficial nature of the implant head with minimal amount of circumferential soft tissue thickness

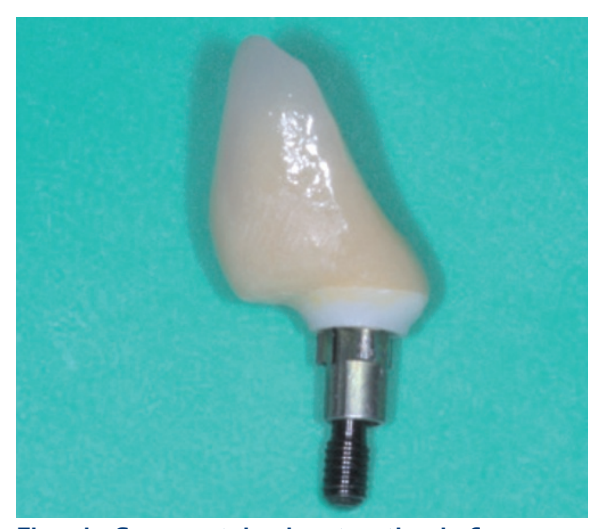

Fig. 7b Screw retained restoration before connection. Note the significant cantilever and abrupt emergence creating a plaque retentive shelf that is likely to harbour bacteria and provide the patient with a significant challenge for personal oral hygiene measures

Table 2 Recommendations on supportive maintenance therapy and restoration type

\begin{tabular}{|l|l|l}
\hline Restoration type & Maintenance interval & Radiography \\
\hline Single tooth crown & $\begin{array}{l}\text { Once a year in absence of risk factors. } \\
\text { Patients at risk require } 6 \text { monthly } \\
\text { contacts at the minimum. }\end{array}$ & $\begin{array}{l}\text { At fit and one year post fit. After this } \\
\text { period radiographs to be taken as and } \\
\text { when clinical signs and symptoms } \\
\text { develop. }\end{array}$ \\
\hline $\begin{array}{l}\text { Bridge with two } \\
\text { implant abutments }\end{array}$ & $\begin{array}{l}\text { Once a year in absence of risk factors. } \\
\text { Patients at risk require } 6 \text { monthly } \\
\text { contacts at the minimum. }\end{array}$ & $\begin{array}{l}\text { At fit and one year post fit. After this } \\
\text { period radiographs to be taken as and } \\
\text { when clinical signs and symptoms } \\
\text { develop. }\end{array}$ \\
\hline $\begin{array}{l}\text { Bridge with more } \\
\text { than two implant } \\
\text { abutments }\end{array}$ & $\begin{array}{l}\text { f months in absence of risk factors. } \\
\text { Patients at risk require 3/4 monthly } \\
\text { contacts at the minimum. Removal of } \\
\text { the restoration on a yearly basis for } \\
\text { thorough debridement. }\end{array}$ & $\begin{array}{l}\text { At fit and one year post fit. After this } \\
\text { period radiographs to be taken as and } \\
\text { when clinical signs and symptoms } \\
\text { develop. }\end{array}$ \\
\hline $\begin{array}{l}\text { Full arch bridgework } \\
\text { retained by implants }\end{array}$ & $\begin{array}{l}\text { 6 months in absence of risk factors. } \\
\text { Patients at risk require 3/4 monthly } \\
\text { contacts at the minimum. Removal of } \\
\text { the restoration on a yearly basis for } \\
\text { thorough debridement. }\end{array}$ & $\begin{array}{l}\text { At fit and one year post fit. After this } \\
\text { period radiographs to be taken as and } \\
\text { when clinical signs and symptoms } \\
\text { develop. }\end{array}$ \\
\hline $\begin{array}{l}\text { Implant retained } \\
\text { dentures }\end{array}$ & $\begin{array}{l}\text { months in absence of risk factors. } \\
\text { Patients at risk require } 3 / 4 \text { monthly } \\
\text { contacts at the minimum. }\end{array}$ & $\begin{array}{l}\text { At fit and one year post fit. After this } \\
\text { period radiographs to be taken as and } \\
\text { when clinical signs and symptoms } \\
\text { develop. }\end{array}$ \\
\hline
\end{tabular}

It may also be associated with the lack of a 'biological seal' around the neck of the implant neck allowing greater potential for microbial colonisation. ${ }^{63,64}$ The importance of optimal oral hygiene to maintain keratinised tissue around implants and planning for implant 


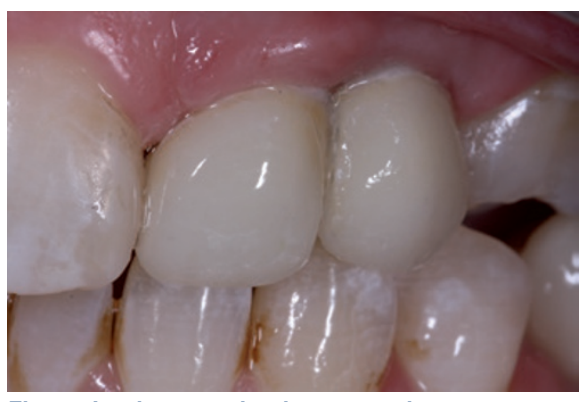

Fig. 8 Implant retained cemented crowns in the 22 and 23 sites. Due to the close proximity of the implants and the uncleansable embrasure space the patient was unable to utilise self-administered hygiene measures

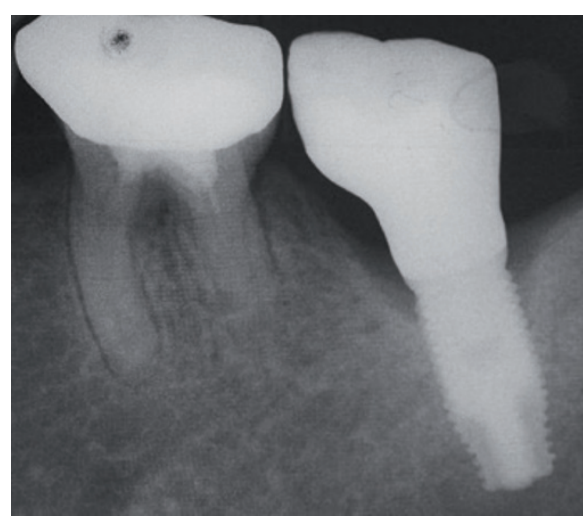

Fig. 9 Implant placed in the $\mathbf{3 7}$ site. The fixture placement was slightly distal to the optimal position resulting in a cantilever to achieve a contact with the adjacent 36 . This cantilever created a stagnation area for plaque, which resulted in peri-mucositis

placement within a zone of keratinised tissue seem to be important factors in preventing peri-implant disease. If feasible, the amount of keratinised tissue can be increased by way of a tissue grafting techniques although the current evidence by way of systematic review failed to show a tangible benefit to patients. ${ }^{65}$

\section{Bone quality}

Bone quality may potentially play a role as a risk factor in peri-implantitis but this has not been fully evaluated. Traditionally bone quality in the maxilla has been considered poorer when compared to the mandible and associated with increased implant failure. However, more recently this has been questioned and it may be that as the bone is different in different sites, placement technique needs to be customised for different sites. When this occurs implant survival is comparable between mandible and maxilla. ${ }^{66}$ This difference could also explain the finding that peri-implantitis seems to be more common in the maxillary arch. ${ }^{67,68}$

Implant survival rates in grafted bone is less than that in native bone but there is as yet no extensive studies examining the incidence of peri-implant disease. ${ }^{69,70} \mathrm{~A}$ study examining the use of iliac crest grafting

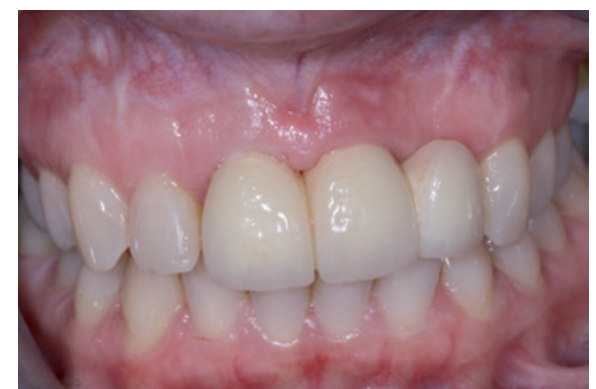

Fig. 10 Implants placed in the 11 and 21 sites with a cantilevered pontic into the 22 site. The embrasure space between the 11 and 21 is limited due to a lack of interproximal soft tissue. The extension of the contact point cervically creates an improved aesthetic result which needs to be balanced against the risk of plaque impaction at the gingival margin

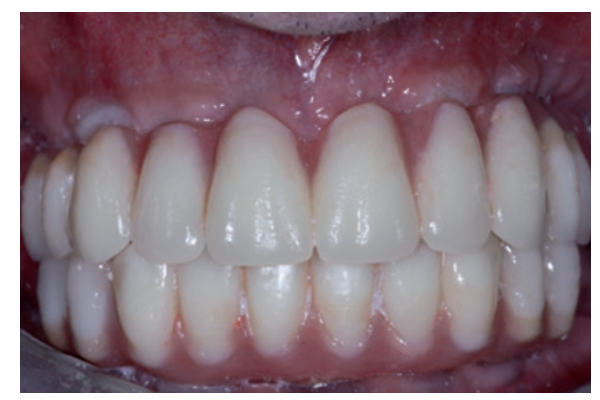

Fig. 11 Fixed hybrid bridgework in the mandible and maxilla supported by a number of implants. Unfortunately the patient found cleaning between the implants and the fit surface of the bridgework very difficult due to the lack of space and cleansability of the prosthesis

for atrophic mandible in 13 patients with 30 implants showed that peri-implantitis developed in $70 \%$ of subjects at ten year follow-up. ${ }^{71}$ Within the same study mean graft resorption was 51\%. Emerging evidence also suggests that vertical and horizontal onlay bone grafting may result in significant resorption, which can result in complete disappearance of the graft. ${ }^{72}$

Graft resorption of this magnitude may correlate with recession and implant exposure resulting in biofilm development resulting in peri-implantitis development (Fig. 6). ${ }^{71}$

In addition grafted bone may react less favourably to a peri-implant inflammation..$^{73,74}$

\section{IMPLANT POSITIONING AND RESTORATION DESIGN}

\section{The prosthetic envelope and hygiene driven implant placement}

Prosthetic driven implant placement, where the ideal implant position creates optimal emergence and a cleansable restoration is also a key factor in the prevention of periimplant infections. ${ }^{75}$ Implants placed too superficially or too palatally results in an abrupt emergence creating a shelf with greater plaque retention (Fig. 7). In contrast implants placed deeply will have a long sub-mucosal component to the restoration and so plaque may be inaccessible to patient oral hygiene measures. Implants placed too buccally are at a risk of developing recession resulting in bacterial colonisation and peri-implant infection. ${ }^{76}$ During an international consensus meeting the need to focus research efforts on the relationship between the development of peri-implantitis in cases where placement is sub-optimal was clearly identified. ${ }^{77}$

Ideally the head of the implant should be positioned horizontally $3 \mathrm{~mm}$ deeper than the adjacent free gingival margin of neighbouring teeth. ${ }^{78}$ There should also be at least $2 \mathrm{~mm}$ of bone buccal to the surface of the implant. ${ }^{78}$ Bodily positioning and angulation should be conducive for ease of restoration cleansability and not solely for the purpose of achieving screw retained restoration.

Where implants are placed too close together interproximal cleaning may be impossible for the patient and difficult to achieve professionally if the restoration suprastructure is not removed (Fig. 8).

In addition, where implants are placed too far from neighbouring teeth stagnation areas can arise due to attempts to achieve a contact point resulting in cantilevering forces non-axially with plaque stagnation areas. (Fig. 9). Due to post extraction bone resorption the absence of an inter-implant papilla is common between neighbouring implant units. ${ }^{79}$ To avoid the so called 'black triangle' appearance of open embrasures, lengthening the contact point results in space closure. Unfortunately the resulting embrasure can be difficult to navigate with interproximal cleaning aids (Fig. 10).

Where multiple teeth or full arches are restored with the use of gingivally coloured materials cleansability of the restoration can be compromised (Fig. 11). The provision of a ridge lap to disguise the interface between the alveolus and the restoration results in a plaque retentive area, while also making oral hygiene measures difficult for the patient. Where gingivally coloured materials are utilised both the technician and clinician should aim to incorporate design features to maintain cleansability of the definitive restoration. ${ }^{80}$

The concept of 'over-engineering' whereby more implants are placed than are required seems now to be difficult to justify. This approach was primarily advocated to prevent occlusal overload or to compensate for early failures. The minimum number of implants should be placed to retain a restoration both for function and aesthetics, making future maintenance simpler. 


\section{The surgical envelope and potential effects on peri-implantitis development}

Placement of dental implants requires an approach that is as atraumatic as possible to prevent unnecessary soft and hard tissue healing changes post-surgery that may result in recession or bone resorption. A physiologically stable envelope of native bone, free from further resorption provides the best prospective implant site. This is best illustrated with problems encountered with implants placed immediately after extraction. A systematic review illustrated that recession and further bone resorption can result when implants are placed in this way. ${ }^{81}$ Loss of the bundle bone, which lines the tooth socket and is intimately associated with the periodontal ligament, can result in unpredictable resorption and the likely loss of the buccal plate. ${ }^{82}$ Implants placed immediately into extraction sockets have shown a greater tendency to develop peri-implantitis. ${ }^{83}$ This may be in part associated with inability to close the site optimally due to a deficit in soft tissue post extraction or early loading of immediate implants resulting in unfavourable forces potentiating post extraction resorption.

The emerging evidence suggests that the utilisation of xenografting/autografting in combination with membrane placement potentially provides a stable bone envelope post extraction. This has been illustrated most recently in a six year CBCT follow-up examination of 20 implants. ${ }^{84}$

Planning implant placement that achieves the ideal functional and aesthetic goals while providing a cleansable restoration needs to be planned in advance of implant placement. Simple methods such as study models and wax set ups can help establish the number of implants required and interproximal distances. Planning trajectories and bodily positioning maybe better achieved utilising advanced imaging and computer aided planning (Fig. 12).

\section{Implant-abutment-restoration interface}

A screw retained option is probably more desirable due to ease of removal, examination and maintenance than a cemented one. Loose abutment and prosthetic screws can, however, present with peri-implant disease symptoms such as mucositis that can, potentially, progress to peri-implantitis. ${ }^{85}$ The implant abutment interface can become populated by microorganisms and their products despite maximum torque levels. ${ }^{86-88}$ For this reason the recommended torque level of the screw should be achieved to ensure optimal long-term fit and location of the restoration.

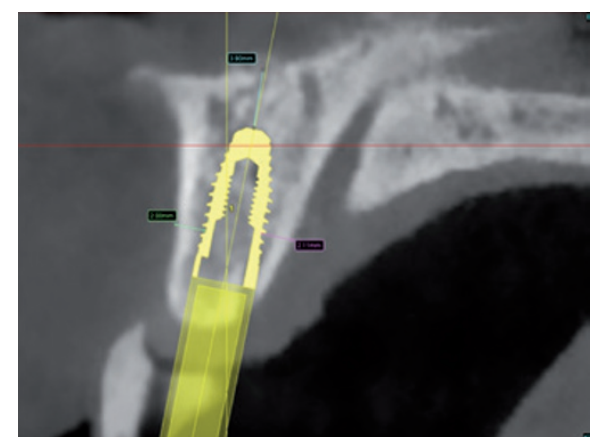

Fig. 12 The utilisation of advanced imaging and implant planning software can aid prosthetically and periodontally driven positioning of implants to minimise the risk of plaque impaction and its sequelae

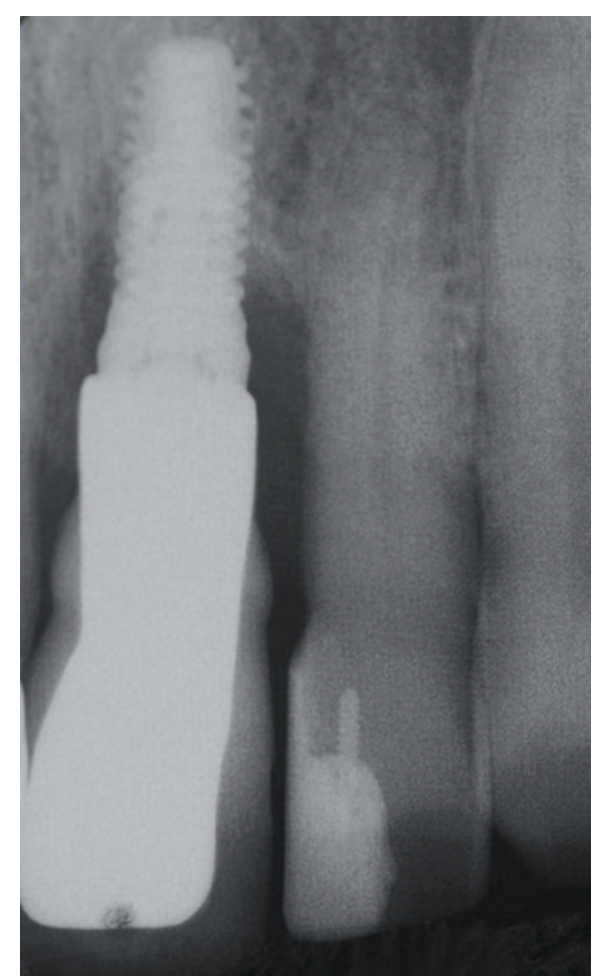

Fig. 13 Long cone periapical radiograph of an implant in the 21 site. This implant was placed significantly deep due to a lack of bone resulting in a long subgingival component to the restoration making the detection of marginal fit problems difficult

The sub-gingival location of implantabutment margins may be unavoidable in the aesthetic zone but this position may lead to suboptimal marginal fit of abutment retained restorations being difficult to detect and can increase susceptibility to biofilm development (Fig. 13). The positioning of the margin supra-gingivally in areas of low aesthetic profile can prevent such problems developing especially where multiple abutments are present, especially where excess cement maybe difficult to remove (Figs 14 and 15). Where cement excess becomes impacted in the peri-implant tissues, peri-implant mucositis and in severe cases a sinus tract and peri-implantitis can

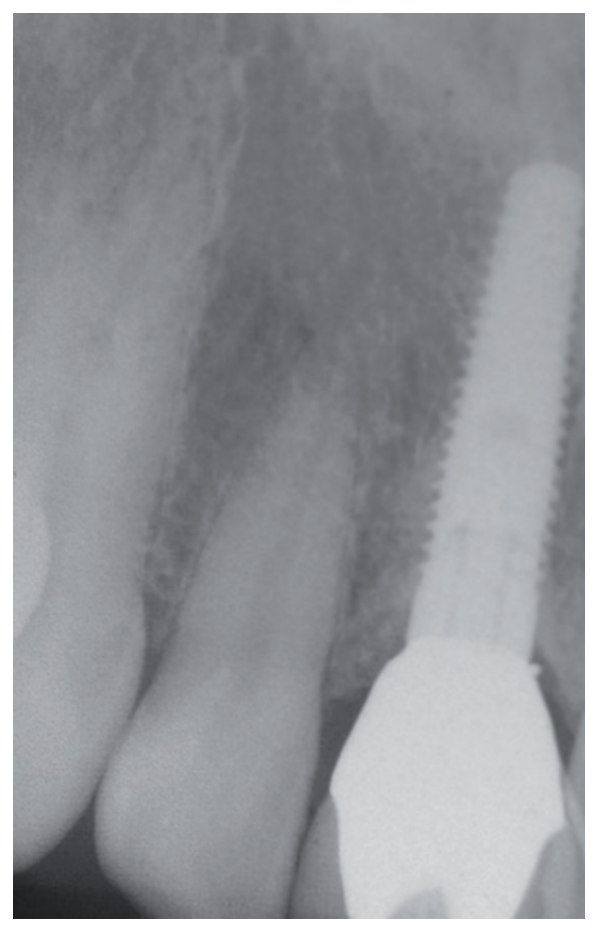

Fig. 14 Peri-implant inflammation and bone loss associated with cement impacted in the mesial aspect of the 11 implant

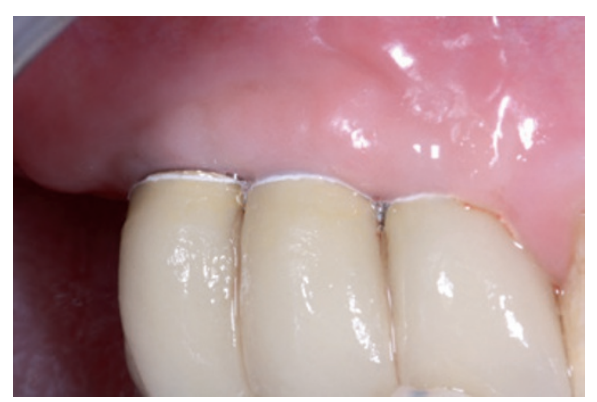

Fig. 15 Purposeful supragingival positioning of cement over crowns in the 12, 13 and 14 sites. Direct visualisation of the restoration margin on seating prevented the impaction of cement into subgingival tissues

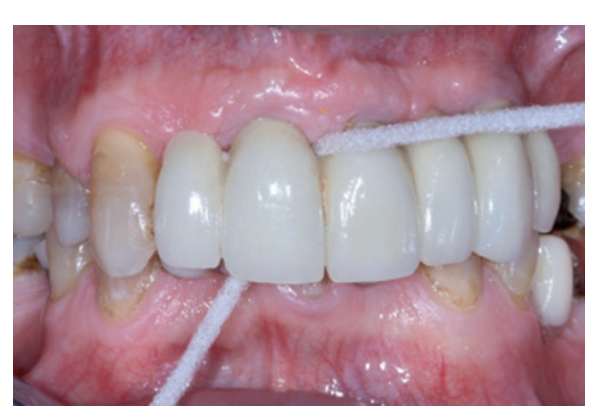

Fig. 16 Utilisation of floss between implants in the 11 and 21 in a multiple implant abutment bridge

result. ${ }^{89}$ Where the abutment is required to be sub-gingival in the aesthetic zone the use of retraction cord during the cement process and floss post-cementation to remove cement is advised. Once a restoration is cemented a radiograph is advised to detect cement excess early and enable it to be removed immediately. 


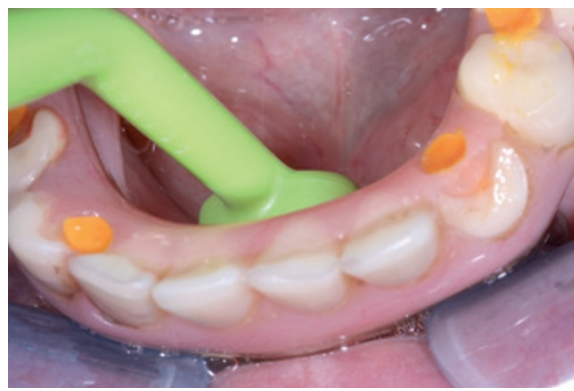

Fig. 17 Utilisation of a contra-angled single tufted brush to cleanse the lingual aspect of fixed bridgework in the mandible

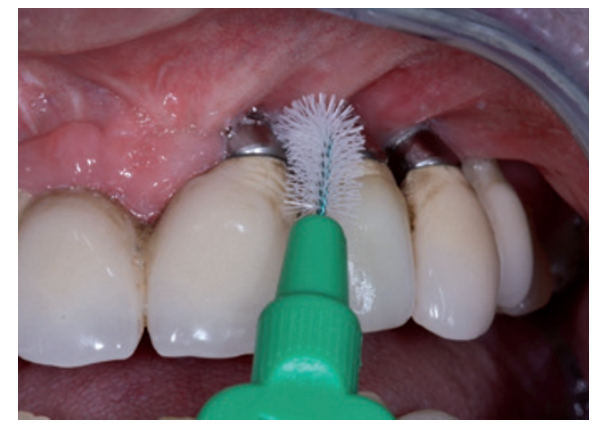

Fig. 18 Angled interproximal brush placed between implants in the 21 and 22 sites

\section{Table 3 Implant maintenance protocol}

Implant maintenance protocol

Prior to maintenance the clinician should review and reassess the following:

Review of medical, social and dental history. Has there been any changes to the medical history that may make the patient more susceptible to periodontal or peri-implant diseases such as diabetes. Have there been any changes in smoking status? Further questioning on occlusal changes such as parafunction and its treatment is advised.

Review of patients symptoms and self-care. Has the patient noticed any changes to the implant site such as bleeding or suppuration? Ask the patient to demonstrate their current hygiene measures for the implant restoration. If the patient complains that they are finding difficulty with hygiene they may require removal of the restoration and its modification to improve cleansability.

\section{Ten point inspection}

\section{Plaque and calculus assessment}

Presence or absence of plaque, calculus or cement should be noted. Oral hygiene should be reinforced at this stage.

\section{Probing \\ The implant should be probed at the same four points and angulations as the initial readings post restoration. If there has been an increase in probing then this may signify peri-implant mucositis or peri-implantitis.}

\section{Bleeding or suppuration}

A positive finding of bleeding indicates inflammation with or without bone loss. Suppuration may mean the presence of advanced peri-implantitis. Pressing the gingival margin may be better to detect suppuration over probing.

\section{Recession}

The presence of progressing recession may ether be a sign of progressive soft tissue changes or associated with mucositis or peri-implantitis.

\section{Mobility}

Any mobility with an implant must be investigated. This suggests either a restorative complication (loose abutment or screw) or complete loss of integration.

\section{Occlusion}

The occlusion of the implant should be kept light enough to allow three layers of shimstock to pass through with the patient in maximum intercuspation as well as in lateral excursions. Any facetting should be investigated.

\section{Contacts}

This should be assessed with floss. A definitive contact point is ideal. A loose or open contact may lead to food impaction which subsequently causes biofilm development on the implant or adjacent tooth.

\section{Percussion sensitivity}

A positive finding may be indicative of a biological or restorative complication.

\section{Radiographic assessment}

If findings from points 1-8 show the possibility of clinical changes relating to a peri-implant infection then a radiograph should be taken. This should be compared to previous radiographs to assess bone levels.

\section{Instrumentation}

This is performed supra-gingivally with a prophy cup and prophy paste. Sub-gingivally a titanium scaler can be used to dislodge any plaque, calculus or cement. A glycine-based air polishing powder can also be used to decontaminate subgingivally, as well as threads of exposed implants. A cotton pledget soaked in Chlorhexidine to swab the area may be utilised as the final step.

The internal spaces within an implant retained restoration can become populated by microorganisms via microleakage around the restoration's access hole and the microgap present between the restoration and the implant head. ${ }^{86,87}$ As a result, microorganisms and their toxins could potentially migrate to the bone-implant interface. The achievement of an optimal restorative seal while maintaining accessibility to the screw
Table 4 Recommendations on oral hygiene measures

Patients should brush their teeth and implants as normal with additional measures extended to implants.

Single tooth implants require flossing at the minimum on a daily basis utilising a crossover floss technique.

Where multiple implants are present patients should be made aware of their location and instructed in techniques to debride the areas under pontics as well as abutments (Fig. 16).

Utilisation of single tufted tooth brushes as well as bristle brushes are invaluable to interproximal cleaning of difficult to reach areas (Figs 17 and 18).

For any given space the largest diameter brush that can passively enter the space should be utilised (Fig. 18).

is desirable in minimising routes for periimplant infection. Various materials have been advocated for access hole filling and subsequent restoration. ${ }^{90,91}$ The placement of a well compacted composite restoration above a non-filamentous non-degradable material such as gutta percha or PTFE appears to provide a predictable seal. ${ }^{90,91}$

\section{MONITORING AND MAINTENANCE INTERVALS}

A five year follow up study of 212 partly edentate patients with dental implants and mucositis who attended maintenance visits were less likely to develop peri-implantitis compared to those who were not maintained. ${ }^{92}$ However, as yet there are no recognised intervals for the monitoring of implants and the peri-implant tissues and the optimum frequency of maintenance. Self-administered methods of biofilm disruption and removal need to be reinforced at every maintenance visit (Figs 16-18) (Tables 2-4).

When considering the planning of maintenance visits awareness of whether the incidence of peri-implantitis is more likely soon after placement needs to be taken into account. ${ }^{93,94}$ As such clinicians may consider a higher recall period in the first five years after placement, which later tails off if no complications arise.

In addition it would seem sensible, as in periodontitis, in patients at a higher risk of developing disease due to systemic or medical/social factors such as smoking should be seen for maintenance more often. Similarly where the implant suprastructure is bulky and presents a challenge for patient self-maintenance then recall interval should be shorter.

. World Health Organization. Global action plan for the prevention and control of noncommunicable diseases: 2013-2020. Geneva: WHO, 2013.

Online plan available at http://apps.who.int/iris/ bitstream/10665/94384/1/9789241506236_eng. pdf?ua=1 (accessed July 2014). 
2. Sanz M, Chapple I L. Clinical research on periimplant diseases: Consensus report of Working Group 4.J Clin Periodonto/ 2012; 39: 202-206.

3. Esposito M, Grusovin M G, Worthington H V. Treatment of peri-implantitis: what interventions are effective? A Cochrane systematic review. Eur J Oral Implantol 2012; 5: S21-41.

4. Grey E B, Harcourt D, O'Sullivan D, Buchanan $H_{1}$ Kilpatrick N M. A qualitative study of patients' motivations and expectations for dental implants. $\mathrm{Br}$ Dent J 2013; 214: E1.

5. Fardal $\emptyset$, Grytten J. A comparison of teeth and implants during maintenance therapy in terms of the number of disease-free years and costs--an in vivo internal control study. J Clin Periodontol 2013; 40: 645-651.

6. Bhatavadekar N. Clinical decisions and the quality of evidence available for dental implants. J Periodontol 2009; 80: 1559-1561.

7. Bhatavadekar N. Helping the clinician make evidence-based implant selections. A systematic review and qualitative analysis of dental implant studies over a 20 year period. Int Dent J 2010; 60: 359-369.

8. Glavind L, Attström R. Periodontal self-examination. A motivational tool in periodontics. J Clin Periodontol 1979; 6: 238-251.

9. Corbella S, Del Fabbro M, Taschieri S, De Siena F, Francetti L. Clinical evaluation of an implant maintenance protocol for the prevention of peri-implant diseases in patients treated with immediately loaded full-arch rehabilitations. Int J Dent Hyg 2011; 9: 216-222.

10. Silverstein L, Garg A, Callan D, Shatz P. The key to success: maintaining the long-term health of implants. Dent Today 1998; 17: 104, 106, 108-111.

11. Graziani F, Figuero E, Herrera D. Systematic review of quality of reporting, outcome measurements and methods to study efficacy of preventive and therapeutic approaches to peri-implant diseases. $J$ Clin Periodontol 2012; 12: 224-244.

12. Strietzel FP. Patient's informed consent before implant-prosthetic treatment: a retrospective analysis of expert opinions. Int J Oral Maxillofac Implants 2003: 18: 433-439.

13. Turani D, Bissett S M, Preshaw P M. Techniques for effective management of periodontitis. Dent Update 2013; 40: 181-184, 187-90, 193.

14. Lindquist $L W$, Carlsson $G E_{1}$ Jemt $T$. Association between marginal bone loss around osseointegrated mandibular implants and smoking habits: a 10-year follow-up study. J Dent Res 1997; 76: 1667-1674.

15. Ferreira S D, Silva G L, Cortelli J R, Costa J E, Costa $\mathrm{F} O$. Prevalence and risk variables for peri-implant disease in Brazilian subjects. J Clin Periodonto/ 2006; 33: 929-935.

16. Serino G, Ström C. Peri-implantitis in partially edentulous patients: association with inadequate plaque control. Clin Oral Implants Res 2009; 20: 169-174.

17. Heitz-Mayfield L J, Needleman I, Salvi G E, Pjetursson B E. Consensus statements and clinical recommendations for prevention and management of biologic and technical implant complications. Int J Oral Maxillofac Implants 2014; 29: 346-350.

18. Quirynen $M$, Vogels R. [Clinical relevance of surface characteristics on the formation of plaque on teeth and implants]. Ned Tijdschr Tandheelkd 2002; 109: 422-429.

19. Renvert S, Persson G R. Periodontitis as a potential risk factor for peri-implantitis. J Clin Periodontol 2009; 10: 9-14.

20. Cho-Yan Lee J, Mattheos N, Nixon K C, Ivanovski S. Residual periodontal pockets are a risk indicator for peri-implantitis in patients treated for periodontitis. Clin Oral Implants Res 2012; 23: 325-333.

21. Bastiaan R J, Waite I M. Effects of tobacco smoking on plaque development and gingivitis. J Periodontol 1978; 49: 480-482.

22. Preber $H$, Kant $T$, Bergström J. Cigarette smoking oral hygiene and periodontal health in Swedish army conscripts. J Clin Periodontol 1980; 7: 106-113.

23. Andrews $J A$, Severson $H H_{\text {, Lichtenstein }}$, Gordon J S. Relationship between tobacco use and selfreported oral hygiene habits. J Am Dent Assoc 1998;
129: $313-320$

24. Clementini M, Rossetti $P H_{1}$ Penarrocha D, Micarelli C, Bonachela W C, Canullo L. Systemic risk factors for peri-implant bone loss: a systematic review and meta-analysis. Int J Oral Maxillofac Surg 2014; 43: 323-334.

25. Heitz-Mayfield L J, Huynh-Ba G. History of treated periodontitis and smoking as risks for implant therapy. Int J Oral Maxillofac Implants 2009; 24: 39-68.

26. Lambert $P$ M, Morris H F, Ochi S. The influence of smoking on 3-year clinical success of osseointegrated dental implants. Ann Periodontol 2000; 5: 79-89.

27. Mombelli A, Müller N, Cionca N. The epidemiology of peri-implantitis. Clin Oral Implants Res 2012; 6: 67-76.

28. Sayardoust $S_{1}$ Gröndahl $K_{1}$ Johansson $E_{1}$ Thomsen $P_{1}$ Slotte C. Implant survival and marginal bone loss at turned and oxidized implants in periodontitissusceptible smokers and never-smokers: retrospective, clinical, radiographic case-control study. J Periodontol 2013; 84: 1775-1782.

29. Dvorak G, Reich K M, Tangl S, Goldhahn J, Haas R, Gruber R. Cortical porosity of the mandible in an osteoporotic sheep model. Clin Oral Implants Res 2011; 22: 500-505

30. Dvorak G, Arnhart $C$, Heuberer $S$, Huber C D, Watzek G, Gruber R. Peri-implantitis and late implant failures in postmenopausal women: a cross-sectional study. J Clin Periodontol 2011; 38: 950-955

31. Dvorak G, Fügl A, Watzek G, Tangl S, Pokorny $P$, Gruber R. Impact of dietary vitamin D on osseointegration in the ovariectomized rat. Clin Oral Implants Res 2012; 23: 1308-1313.

32. Ferreira $S D$, Silva $G L$, Cortelli J R, Costa J E, Costa $F 0$. Prevalence and risk variables for peri-implant disease in Brazilian subjects. J Clin Periodontol 2006; 33: 929-935.

33. Venza I, Visalli M, Cucinotta M, De Grazia G, Teti $D$. Venza M. Proinflammatory gene expression at chronic periodontitis and peri-implantitis sites in patientswith or without type 2 diabetes. $J$ Periodontol 2010; 81: 99-108.

34. López-Cedrún J L, Sanromán J F, García A et al. Oral bisphosphonate-related osteonecrosis of the jaws in dental implant patients: a case series. Br J Oral Maxillofac Surg 2013; 51: 874-879.

35. Chambrone L, Mandia J Jr, Shibli J A, Romito G A, Abrahao M. Dental implants installed in irradiated jaws: a systematic review. J Dent Res 2013; 92: 119S-30S.

36. Fejerskov O, Escobar G, Jøssing M, Baelum V. A functional natural dentition for all- and for life? The oral healthcare system needs revision. J Oral Rehabil 2013; 40: 707-722

37. Antoniazzi R P, Miranda L A, Zanatta F B et al. Periodontal conditions of individuals with Sjögren's syndrome. J Periodonto/ 2009; 80: 429-435.

38. Habbab K M, Moles D R, Porter S R. Potential ora manifestations of cardiovascular drugs. Oral Dis 2010; 16: 769-773.

39. Smidt $D$, Torpet $L A$, Nauntofte $B$, Heegaard K M, Paedersen A M. Associations between oral and ocular dryness, labial and whole salivary flow rates, systemic diseases and medications in a sample of older people. Community Dent Oral Epidemio/2011; 39: $276-288$.

40. Marrone A, Lasserre J, Bercy P, Brecx M C. Prevalence and risk factors for peri-implant disease in Belgian adults. Clin Oral Implants Res 2013; 24: 934-940.

41. Renvert S, Lindahl C, Rutger Persson G. The incidence of peri-implantitis for two different implant systems over a period of thirteen years. $J$ Clin Periodontol 2012; 39: 1191-1197.

42. Hernández G, Lopez-Pintor R M, Arriba L, Torres J, de Vicente J C. Implant treatment in patients with oral lichen planus: a prospective-controlled study. Clin Oral Implants Res 2012; 23: 726-732.

43. Block M S, Kent J N. Factors associated with soft-and hard-tissue compromise of endosseous implants. J Oral Maxillofac Surg 1990; 48: 1153-1160.

44. López-Jornet P, Camacho-Alonso F, Sánchez-Siles M. Dental implants in patients with oral lichen planus: a cross-sectional study. Clin Implant Dent Relat Res 2014; 16: 107-115.

45. Gruica B, Wang H Y, Lang N P, Buser D. Impact of IL-1 genotype and smoking status on the prognosis of osseointegrated implants. Clin Oral Implants Res 2004; 15: 393-400.

46. Laine $\mathrm{M} \mathrm{L}$, Leonhardt $\mathrm{A}$, Roos-Jansåker $\mathrm{A} M$ et al. IL-1RN gene polymorphism is associated with peri-implantitis. Clin Oral Implants Res 2006; 17: 380-385.

47. Bormann K H, Stühmer C, Z'Graggen M, Kokemöller H, Rücker M, Gellrich N C. IL-1 polymorphism and periimplantitis. A literature review. Schweiz Monatsschr Zahnmed 2010; 120: 510-520.

48. Isidor F. Loss of osseointegration caused by occlusal load of oral implants. A clinical and radiographic study in monkeys. Clin Oral Implants Res 1996; 7 : 143-152.

49. Misch C E, Suzuki J B, Misch-Dietsh F M, Bidez M W A positive correlation between occlusal trauma and peri-implant bone loss: literature support. Implant Dent 2005; 14: 108-116.

50. Klinge B, Meyle J; Working Group 2. Peri-implant tissue destruction. The Third EAO Consensus Conference 2012. Clin Oral Implants Res 2012; 6: 108-110.

51. Fu J H, Hsu Y T, Wang H L. Identifying occlusal overload and how to deal with it to avoid marginal bone loss around implants. Eur J Oral Implantol 2012; 5: S91-103.

52. Stanford C M, Brand R A. Toward an understanding of implant occlusion and strain adaptive bone modeling and remodeling. J Prosthet Dent 1999; 81 : 553-561.

53. Miyata $T$, Kobayashi $Y$, Araki H, Ohto T, Shin K. The influence of controlled occlusal overload on periimplant tissue. part 4: a histologic study in monkeys. Int J Oral Maxillofac Implants 2002; 17: 384-390.

54. Davies S J. Occlusal considerations in implantology: good occlusal practice in implantology. Dent Update 2010; 37: 610-612, 615-616, 619-20.

55. Siddiqi A, Payne A G, De Silva R K, Duncan W J. Titanium allergy: could it affect dental implant integration? Clin Oral Implants Res 2011; 22: 673-680.

56. Oliva X, Oliva J, Oliva J D. Full-mouth oral rehabilitation in a titanium allergy patient using zirconium oxide dental implants and zirconium oxide restorations. A case report from an ongoing clinical study. Eur J Esthet Dent 2010; 5: 190-203.

57. Javed F, Al-Hezaimi K, Almas K, Romanos G E. Is titanium sensitivity associated with allergic reactions in patients with dental implants? A systematic review. Clin Implant Dent Relat Res 2013; 15: 47-52.

58. Mouhyi J, Dohan Ehrenfest D M, Albrektsson T. The peri-implantitis: implant surfaces, microstructure, and physicochemical aspects. Clin Implant Dent Relat Res 2012; 14: 170-183.

59. Greenstein $\mathrm{G}$, Cavallaro J. The clinical significance of keratinized gingiva around dental implants. Compend Contin Educ Dent 2011; 32: 24-31.

60. Gobbato L, Avila-Ortiz G, Sohrabi K, Wang C W, Karimbux N. The effect of keratinized mucosa width on peri-implant health: a systematic review. Int J Oral Maxillofac Implants 2013: 28: 1536-1545.

61. Lin $\mathrm{G} \mathrm{H}$, Chan $\mathrm{H} \mathrm{L}$, Wang $\mathrm{H}$ L. The significance of keratinized mucosa on implant health: a systematic review. J Periodontol 2013; 84: 1755-1767.

62. Yeung S C. Biological basis for soft tissue management in implant dentistry. Aust Dent J 2008; 1: $539-42$.

63. Calvo Mateo M A, Ruiz Marcellan M C, Bañares Agustin M V. Padros Fradrera A, Sada Moreno E. Morphological and immunohistochemical aspects of the biological seal in Klöckner's dental implants: study of 15 cases. Implant Dent 1998; 7: 103-112.

64. Etter T H, Håkanson I, Lang N P, Trejo P M, Caffesse R G. Healing after standardized clinical probing of the perlimplant soft tissue seal: a histomorphometric study in dogs. Clin Oral Implants Res 2002; 13: 571-580.

65. Esposito M, Maghaireh H, Grusovin M G, Ziounas I, Worthington H V. Soft tissue management for dental implants: what are the most effective techniques? A Cochrane systematic review. Eur J 
Oral Implantol 2012; 5: 221-238.

66. Friberg B, Ekestubbe A, Sennerby L. Clinical outcome of Brånemark System implants of various diameters: a retrospective study. Int J Oral Maxillofac Implants 2002; 17: 671-677.

67. Esposito M, Hirsch J M, Lekholm U, Thomsen P. Biological factors contributing to failures of osseointegrated oral implants. (II). Etiopathogenesis. Eur J Oral Sci 1998; 106: 721-764.

68. Kourtis S G Sotiriadou S, Voliotis S, Challas A. Private practice results of dental implants. Part I: survival and evaluation of risk factors-Part II: surgical and prosthetic complications. Implant Dent 2004; 13: 373-385

69. Waasdorp J, Reynolds M A. Allogeneic bone onlay grafts for alveolar ridge augmentation: a systematic review. Int J Oral Maxillofac Implants 2010; 25: 525-531.

70. Donos N, Mardas N, Chadha V. Clinical outcomes of implants following lateral bone augmentation: systematic assessment of available options (barrier membranes, bone grafts, split osteotomy). J Clin Periodontol 2008; 35: 173-202.

71. Verhoeven J W, Cune M S, Terlou M, Zoon MA, de Putter $\mathrm{C}$. The combined use of endosteal implants and iliac crest onlay grafts in the severely atrophic mandible: a longitudinal study. Int J Oral Maxillofac Surg 1997; 26: 351-357.

72. Sbordone C, Toti P, Guidetti F, Califano L, Santoro A, Sbordone L. Volume changes of iliac crest autogenous bone grafts after vertical and horizontal alveolar ridge augmentation of atrophic maxillas and mandibles: a 6-year computerized tomographic follow-up. J Oral Maxillofac Surg 2012; 70: 2559-2565.

73. Yerit K C, Posch M, Hainich S et al. Long-term implant survival in the grafted maxilla: results of a 12-year retrospective study. Clin Oral Implants Res 2004; 15: 693-699.

74. Sbordone L, Toti P, Menchini-Fabris G, Sbordone C, Guidetti F. Implant survival in maxillary and mandibular osseous onlay grafts and native bone: a 3-year clinical and computerized tomographic follow-up. Int J Oral Maxillofac Implants 2009; 24: 695-703.

75. Alani A, Corson M. Soft tissue manipulation for single implant restorations. Br Dent J 2011; 211: 411-416.

76. Hsu Y T, Shieh C H, Wang H L. Using soft tissue graft to prevent mid-facial mucosal recession following immediate implant placement. J Int Acad Periodontol 2012; 14: 76-82.

77. Sanz M, Chapple I L; Working Group 4 of the VIII European Workshop on Periodontology. Clinical research on peri-implant diseases: consensus report of Working Group 4. J Clin Periodontol 2012; 12: 202-206.

78. Rojas-Vizcaya F. Biological aspects as a rule for single implant placement. The $3 \mathrm{~A}-2 \mathrm{~B}$ rule: a clinical report. J Prosthodont 2013; 22: 575-580.

79. Tarnow D P, Magner A W, Fletcher P. The effect of the distance from the contact point to the crest of bone on the presence or absence of the interproximal dental papilla. J Periodontol 1992; 63: 995-996.

80. Alani A, Maglad A, Nohl F. The prosthetic management of gingival aesthetics. Br Dent J 2011 210: 63-69.

81. Cosyn J, Hooghe N, De Bruyn H. A systematic review on the frequency of advanced recession following single immediate implant treatment. J Clin Periodontol 2012; 39: 582-589.

82. Araújo M G, Wennström J L, Lindhe J. Modeling of the buccal and lingual bone walls of fresh extraction sites following implant installation. Clin Oral Implants Res 2006; 17: 606-614.

83. Rodrigo D, Martin C, Sanz M. Biological complications and peri-implant clinical and radiographic changes at immediately placed dental implants. A prospective 5-year cohort study. Clin Oral Implants Res 2012; 23: 1224-1231.

84. Buser D, Chappuis V, Kuchler U et al. Long-term stability of early implant placement with contou augmentation. J Dent Res 2013; 92: 176S-82S.
85. Camargos Gde V, do Prado CJ, das Neves F D, Sartor I A. Clinical outcomes of single dental implants with external connections: results after 2 to 13 years. Int J Oral Maxillofac Implants 2012; 27: 935-944.

86. Aloise J P, Curcio R, Laporta M Z, Rossi L, da Silva A M, Rapoport A. Microbial leakage through the implant-abutment interface of Morse taper implants in vitro. Clin Oral Implants Res 2010; 21: 328-335.

87. Harder S, Dimaczek B, Açil Y, Terheyden H, Freitag-

Wolf S, Kern M. Molecular leakage at implantabutment connection-in vitro investigation of tightness of internal conical implant-abutment connections against endotoxin penetration. Clin Oral Investig 2010; 14: 427-432.

88. Teixeira W, Ribeiro R F, Sato S, Pedrazzi V. Microleakage into and from two-stage implants: an in vitro comparative study. Int J Oral Maxillofac Implants 2011; 26: 56-62.

89. Shapoff C A, Lahey B J. Crestal bone loss and the consequences of retained excess cement around dental implants. Compend Contin Educ Dent 2012; 33: 94-96, 98-101.

90. Park S D, Lee Y, Kim Y L, Yu S H, Bae J M, Cho H W. Microleakage of different sealing materials in access holes of internal connection implant systems. $J$ Prosthet Dent 2012; 108: 173-180.

91. Moráguez 0 D, Belser U C. The use of polytetrafluoroethylene tape for the management of screw access channels in implant-supported prostheses. J Prosthet Dent 2010; 103: 189-191.

92. Costa F O, Takenaka-Martinez S, Cota L O, Ferreira S D, Silva G L, Costa J E. Peri-implant disease in subjects with and without preventive maintenance: a 5-year follow-up. J Clin Periodonto/ 2012; 39: 173-181.

93. Charalampakis G, Rabe P, Leonhardt A, Dahlén G. A follow-up study of peri-implantitis cases after treatment. J Clin Periodonto/ 2011; 38: 864-871.

94. Renvert S, Lindahl C, Rutger Persson G. The incidence of peri-implantitis for two different implant systems over a period of thirteen years. $J$ Clin Periodontol 2012; 39: 1191-1197. 